\title{
Arginine deprivation: a potential therapeutic for cancer cell metastasis? A review
}

\author{
Houssam Al-Koussa ${ }^{\dagger}$, Nour El Mais ${ }^{\dagger}$, Hiba Maalouf, Ralph Abi-Habib and Mirvat El-Sibai ${ }^{*}$ (i)
}

\begin{abstract}
Arginine is a semi essential amino acid that is used in protein biosynthesis. It can be obtained from daily food intake or synthesized in the body through the urea cycle using L-citrulline as a substrate. Arginine has a versatile role in the body because it helps in cell division, wound healing, ammonia disposal, immune system, and hormone biosynthesis. It is noteworthy that L-arginine is the precursor for the biosynthesis of nitric oxide (NO) and polyamines. In the case of cancer cells, arginine de novo synthesis is not enough to compensate for their high nutritional needs, forcing them to rely on extracellular supply of arginine. In this review, we will go through the importance of arginine deprivation as a novel targeting therapy by discussing the different arginine deprivation agents and their mechanism of action. We will also focus on the factors that affect cell migration and on the influence of arginine on metastases through polyamine and $\mathrm{NO}$.
\end{abstract}

Keywords: Arginine, Arginase, Cell migration, Rho-GTPases

\section{Background}

Cancer is associated with high mortality rates although significant improvements have been made in early detection and treatment $[1,2]$. The most potent and conventional approach involves the usage of chemotherapy, radiotherapy, and surgery depending on the type and stage of the tumor [3, 4]. However, such cytotoxic and nonselective approaches could lead to severe damage to normal cells [1]. This opened the door for more selective approaches, including stem cell therapy, hormone therapy, immunotherapy and amino acid deprivation therapy [5-8]. The latter depends on the fact that cancer cells proliferate at a much higher rate than normal cells, requiring higher amounts of nutrients and exceeding their own capability to synthesize amino acids $[9,10]$. Therefore, nonessential amino acids become essential, and the cancer cell becomes auxotrophic to them [11,

\footnotetext{
*Correspondence: mirvat.elsibai@lau.edu.lb

${ }^{\dagger}$ Houssam Al-Koussa and Nour El Mais contributed equally to this work Department of Natural Sciences, School of Arts and Sciences, Lebanese American University, P.O. Box: 13-5053, Chouran, 11022801 Beirut, Lebanon
}

12]. This method is even more effective when the normal metabolism of a certain amino acid is disrupted in the cancer cell, making the cell more dependent on the environment and thus making the therapy more selective and efficient [13].

One of the promising amino acid deprivation therapies is arginine deprivation, which is based on introducing an arginine-depleting agent. Arginine is a semi essential amino acid; it is taken from dietary sources and synthesized through the urea cycle in the kidneys. Some types of cancer cells require arginine for growth, making them either arginine auxotrophic or partially auxotrophic. Interestingly, different studies showed that cancer cell migration has been affected by the depletion of arginine. Although motility is a normal physiological process associated with wound healing, embryonic development, and immune responses, it is a process used by cancer cells to metastasize to other organs $[14,15]$. Therefore, the depletion of arginine impairs the cancer cell's ability to metastasize. However, the mechanism of impairment is still under investigation.

In this review, we will briefly discuss how arginine deprivation could be used as a targeting therapeutic for both 
arginine auxotrophic and partially auxotrophic types of cancer. Moreover, we will give examples of the different types of arginine deprivation agents and their mechanism of action. Then, we will introduce the role of arginine deprivation in effecting cell migration through $\mathrm{NO}$ and polyamines. Finally, we will discuss other factors coordinating motility along with the role of RhoA, Rac1, and Cdc42 in invasion, focal adhesions formation and cell motility.

\section{Arginine}

Arginine is considered a non-essential amino acid since the cell is capable of synthesizing its own arginine. However, when it is under catabolic stress, it relies heavily on acquiring arginine from the environment, making arginine "conditionally" essential $[13,16]$. The synthesis of arginine is done through the urea cycle, which normally takes place in the kidney. The de novo synthesis of arginine includes the conversion of L-citrulline, by arginosuccinate synthetase (ASS1) and arginosuccinate lyase (ASL), to arginine [13]. Consequently, the addition of L-citrulline to arginine deprived cancer cells could rescue the cells and increase the flux of its urea cycle [17-19]. This is accomplished by the ASS1 enzyme that catalyzes the conversion of L-citrulline and aspartic acid to arginosuccinate, which is then converted by ASL to L-arginine and fumaric acid. L-ornithine could also be a substrate to produce arginine through its conversion by ornithine transcarbamylase (OCT). Some tumors have their arginine metabolizing enzymes downregulated, preventing them from producing arginine from available substrates and making them arginine auxotrophic [20-22].

\section{Arginine depriving agents}

One of the first arginine deprivation agents to be synthesized was arginine deaminase (ADI), which metabolizes arginine, preventing cells in culture from growing [23]. However, it had limitations such as it is only effective on cancer cells lacking the ASS1 enzyme, it has low serum half-life, and it is highly immunogenic [24, 25]. To address such problems, polyethylene glycol (PEG) was attached to it, and it was given in high doses to increase efficiency [13, 23].

Synthesized human Arginase 1 (HuArgI) is another arginine deprivation agent that was used to target arginine in auxotrophic cancer cell lines. However, due to its limitations, it was enhanced by adding PEG and substituting $\mathrm{Mn}^{2+}$ with $\mathrm{Co}^{2+}$ to become HuArgI (Co)PEG5000, which lasts longer in serum, has an improved catalytic activity and is less exposed to the immune system $[17,26,27]$.

\section{Implication of arginine deprivation on cancer therapy}

If the cells were not rescued upon adding L-citrulline after arginine depletion, then the cells exhibit arginine auxotroph. For example, L-citrulline failed to rescue ovarian cancer cell lines, SKOV3 and PA1, from cytotoxicity after arginine deprivation. Thus, those cell lines are completely auxotrophic to arginine. However, $\mathrm{CaOV} 3$, a third ovarian cancer cell line, was rescued upon the addition of L-citrulline, making this cell line a partially auxotrophic one [17]. Similarly, in the case of pancreatic cancer cells some cell lines were rescued when L-citrulline was added to them while others were not $[17,28]$. Moreover, in the case of colorectal cancer, all the tested cell lines, including Caco-2, were rescued when adding L-citrulline, making them partial auxotrophic [29].

Depriving cancer cells from arginine does not only have a cytotoxic effect but also induces cell cycle arrest in some types of cancer cells. Cell cycle analysis was done on the surviving population of ovarian and pancreatic cancer cells to examine the effect of arginine deprivation on the cell cycle. Upon the addition of HuArgI (Co)-PEG5000 to several ovarian and pancreatic cancer cell lines, results showed that there was a cell cycle arrest at G0/G1 after $48 \mathrm{~h}$ and $72 \mathrm{~h}$ of treatment, respectively $[17,28]$. Results also demonstrated a decrease in the number of cells present at the S and G2 phase, showing that arginine caused cell cycle arrest to the surviving ovarian cancer cells [17].

Different types of tumors undergo different mechanisms of cell death when deprived from arginine. Some tumors like acute lymphoblastic leukemia (ALL) and hepatocellular carcinoma exhibit cell death by apoptosis while other types of cancer cells like ovarian, pancreatic, acute myeloid leukemia (AML), and glioblastoma multiforme (GBM) showed a caspase-independent, non-apoptotic cell death $[17,18,28,30]$. The latter is a process known as autophagy, which is when the cell degrades itself to form missing nutrients in response to starvation. Thus, this process is the first protective mechanism against cell death, yet on the long term it results in non-apoptotic death [17, 19, 31]. Chloroquine (CQ), an autophagy inhibitor, was added to ovarian, pancreatic, AML, and GBM cells when treated with HuArgI (CO) PEG-5000. As expected, autophagy was inhibited and the drug's cytotoxicity decreased, indicating that the cells were dying after treatment by autophagy. Moreover, there were no caspase activation and no loss in the membrane integrity, proving that cell death was not due to apoptosis $[17,28]$. 


\section{The effects of arginine deprivation on cell migration} and invasion

After highlighting the role of arginine depletion on cell viability, it is important to look at its effect on cell migration. The enzyme ASS1 is important in the synthesis of arginine de novo by the cell. The absence or presence of ASS1 differentiate the cancer cell lines into arginine complete auxotrophic or partial auxotrophic, respectively [17, 18, 28, 30]. A previous study proved that ASS1 is expressed in human gastric cancer cell lines and its suppression efficiently hinders gastric cancer cell lines metastatic capabilities in vitro and in vivo. Moreover, this study indicated that when the levels of arginine drops, and it is accompanied with silencing the expression of ASS1, gastric cancer cell lines migration capability got hindered [32]. In another study, a western blot was performed on colon cancer Caco-2 cell line, showing a decrease in the level of ASS1 expression after the cells were deprived from arginine by HuArgI (Co)-PEG 5000. However, the levels of ASS1 expression were restored with the addition of L-citrulline [29]. This indicates that ASS1 expression and arginine concentration play a crucial role in cancer metastasis.

Arginine dependent migration requires arginine to be metabolized by two major enzymes, arginase 1 (Arg1) and nitric oxide synthase (NOS). The latter metabolizes arginine to NO and citrulline [33]. During the process of wound healing, the levels of NO elevate, promoting cell migration and proliferation $[34,35]$. In case of arginine dependent cell migration, L-arginine is converted to L-citrulline and NO. This NO activates Focal adhesion kinase (FAK) signaling cascade, which internalizes integrin and regulates focal adhesion (FA) assembly and disassembly (Figs. 1 and 2). Thus, when arginine was depleted from the environment using $\mathrm{HuArgI}(\mathrm{Co})$-PEG5000, the wound healing assay results showed a decrease in the colorectal cancer cells' migration capability. However, when L-citrulline was added with the treatment, the rate of cell migration was restored [29]. Moreover, in another study, normal intestinal cells were supplied with NOS inhibitors, which resulted in a decrease in cell migration. However, when NOS was added in the presence of arginine and NO secondary messenger in post-injury intestinal epithelial cells, cell migration was directly stimulated [36, 37]. This finding was supported by several studies done on other epithelial cell types [37].

Depriving the cell from arginine also plays a role in decreasing the cell's capability in adhering to the ECM; this was observed in cell adhesion assay done on Caco-2 cells. For the cell to adhere and migrate properly, an interaction between FA molecules and actin cytoskeleton is necessary in the presence of FAK [38]. A study done on human intestinal epithelial cells showed that FAK plays a crucial role in inducing adhesion to the ECM

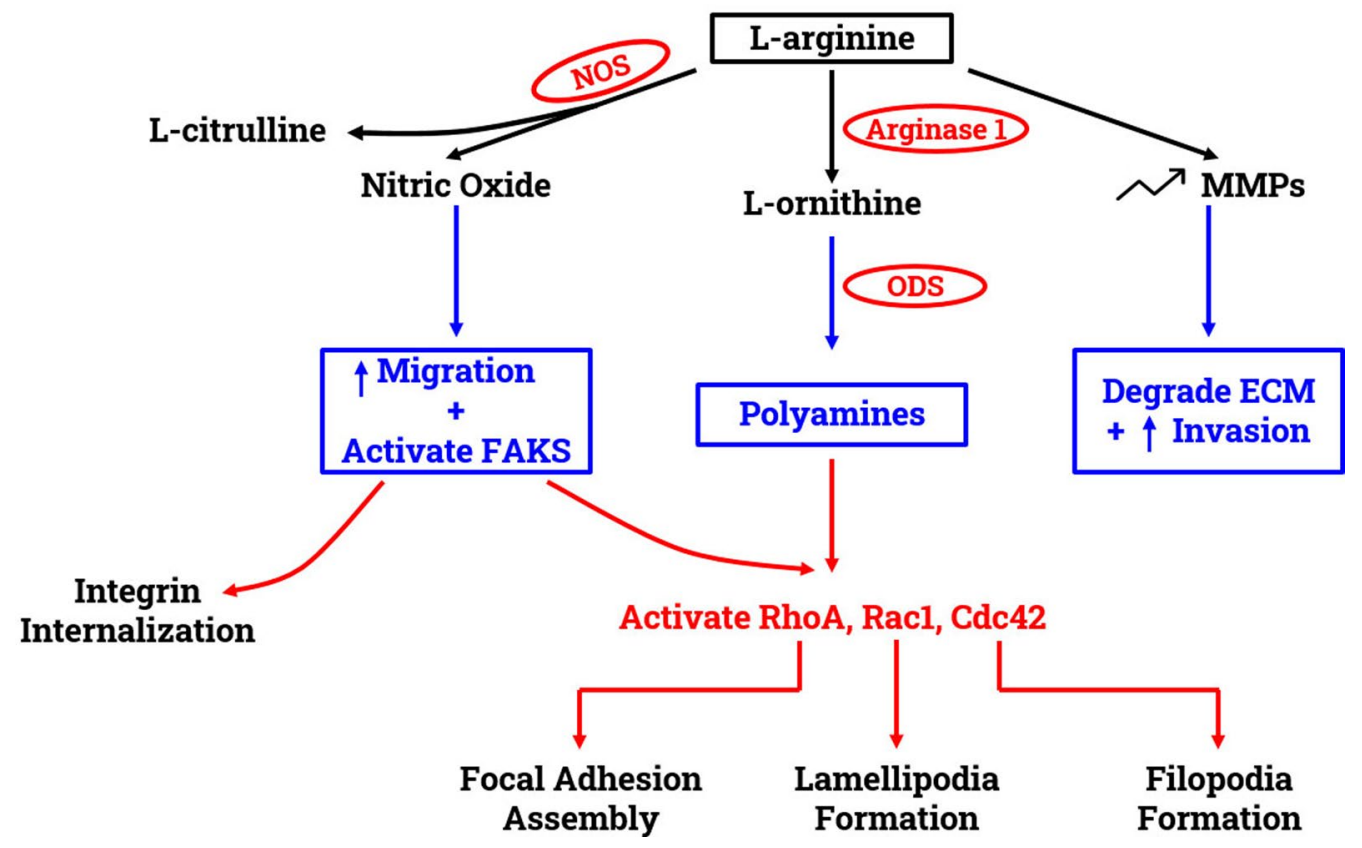

Fig. 1 Effect of arginine on migration and invasion. The utilization of L-arginine by NOS produces L-citrulline and nitric oxide. The latter promotes cell migration and activates the focal adhesion kinases (FAKS). Activated FAKs induce the internalization of integrins. L-arginine is also metabolized by Arginase 1 to produce L-ornithine with is in turn utilized by ODS to produce polyamines. Polyamines stimulates the activation of the small Rho GTPases RhoA, Rac1 and Cdc42. L-arginine increases the expression of MMPs, which results in an increased matrix degradation and invasion 


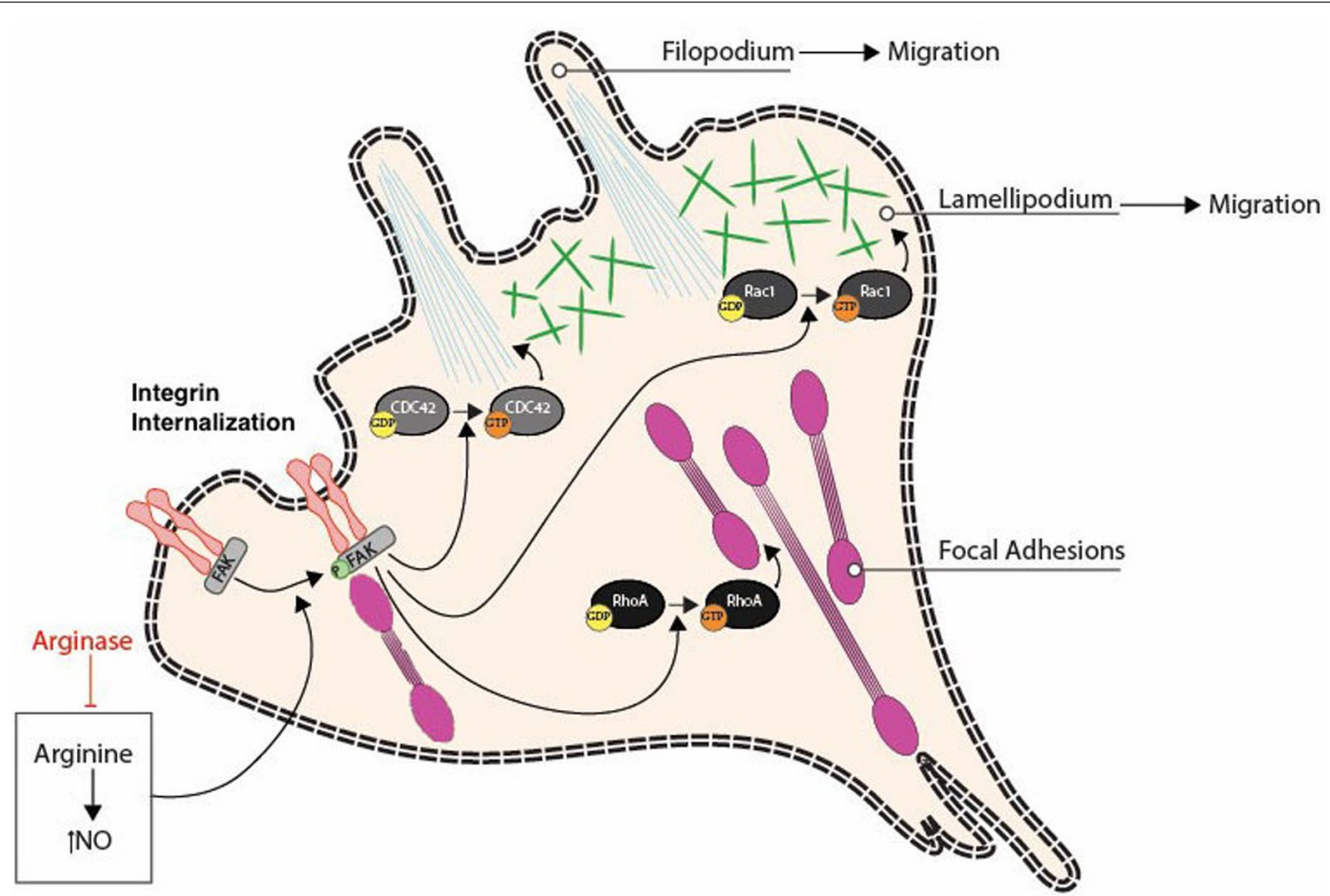

Fig. 2 Arginase inhibits cytoskeletal reorganization needed for cell migration. Upon the production of nitric oxide from L-arginine, FAK gets phosphorylated activating Cdc42, Rac1 and RhoA by replacing GDP with GTP. Collectively, RhoGTPases lead to the regulation of the actin cytoskeleton and the formation of actin structures and dynamics needed for cell migration, such as filopodia and lamellipodia formation and focal adhesion dynamics. These are required for cancer cell migration, hence arginase leads to the inhibition of cancer cell migration through the inhibition of these events

[39]. Moreover, when FAK was inhibited, cell migration got hindered by preventing the newly formed protrusion from getting fixed on the ECM [36]. Immunostaining analysis of FA structure of colorectal cancer cells revealed that the size of FA appears to be smaller after arginine deprivation. Hence, the latter hindered the maturation of FAs, impairing cellular adhesion [29]. Other studies showed that NO and arginine increase FAK phosphorylation with arginine being the main contributor $[35,36]$.

In addition to NOS, the intracellular Arg1 enzyme also utilizes arginine. It converts arginine to ornithine, which is the precursor of polyamines. One of the enzymes used in polyamine biosynthesis is ornithine decarboxylase (ODC). Polyamine is required during cell migration for forming lamellipodia, stress fibers, and integrin subunit a1. It also increases the $\mathrm{K}+$ channel mediated $\mathrm{Ca}^{2+}$ influx and aids FAK in inducing paxillin phosphorylation [32, 39-42]. Targeted inhibition of ODC was correlated with abnormal morphology of actin-cytoskeleton of metastatic cells during migration. Moreover, exogenous supply of polyamine putrescine was able to restore cellular morphology and migration capabilities [36, 43, 44]. A study suggested that Arg1 could be a prognostic biomarker for hepatocellular carcinoma (HCC) patients because higher levels of Arg1 was associated with aggressive tumor growth, higher levels of alanine, aminotransferase, and glutamyltranferase. Overexpression of Arg1 significantly increased cell migration while knocking down Arg1 reduced cell migration when tested on Huh7, liver cell, in vitro [45].

Depriving the cell from arginine also decreases the cells' capability to break through the ECM and invade. For the cancer cell to remodel the ECM and facilitate invasion, it utilizes matrix metalloproteinases (MMPs), a family of extracellular zinc-dependent proteinases. They can degrade the ECM macromolecules, removing the physical barrier that is stopping the tumor cells from invasion [46, 47]. MMPs are numerous and produced in their inactive state, so they require proteolytic remodeling to become active. These enzymes can adjust signals and physiological processes to establish molecular communication between the tumor cells and the host tissue stroma [47, 48]. Invasion assay results showed that arginine depletion hindered the colorectal cancer cells' invasive capability. These results were supported by western blots done for MMP2 and MMP9. The blots indicated a significant decrease in MMP expression levels when the cells were treated with HuArgI(Co)-PEG5000 [29] (Fig. 1). Another study done on hepatocellular carcinoma cells Huh7 showed that overexpression and 
downregulation of Arg1 enhances and hinders the Huh7 invasive capabilities, respectively. The study also introduced the role of Arg1 as a crucial element in promoting cell migration and invasion through enhancing the epithelial-to-mesenchymal transition [45].

Different regulatory signals, at the leading and trailing ends of the cell, work on mediating cell migration [48]. These signals include Rho GTPases, PI3K, integrins and microtubules, whose interlink and positive feedback loops regulate cell polarity $[41,49,50]$. The most significant Rho GTPases are RhoA, Rac1 and Cdc42 that regulate cell adhesion, migration, and invasion. Moreover, they also play an important role in regulating intracellular junctions and cell to ECM interactions [51-55]. When polyamine is depleted, all three Rho-GTPases' functions (RhoA, Rac1, and Cdc42) are affected, which in turn affects cell migration (Figs. 1 and 2). RhoA assembles focal adhesions, Cdc42 regulates the formation of filopodia, and Rac1 regulates the formation of lamellipodia [51, 53-55]. Arginine depletion hinders the activation of RhoA in colorectal cancer cells which was evident by fluorescence energy transfer (FRET) using a CFP/YPF biosensor [29]. In another study, NO was shown to stimulate Cdc42 and Rac1, which activate Hypoxia-inducible factor 1 (HIF-1) that promotes macrophage migration [56]. Moreover, a study reported that an increase in NO levels cause an increase in pancreatic cancer cells invasiveness through RhoA activation [35, 57] (Fig. 2).

\section{Conclusion}

Many malignant tumors featured high metabolic demand for specific amino acids to meet their rapid growth. Thus, amino acid deprivation is a novel therapy with arginine as a major target. Arginine is known to be a nutritionally essential amino acid with the ability to regulate cell activities and influence cancer cell's vitality, motility, adhesion, and invasion. Numerous clinical investigations are being held in order to fully grasp the efficiency of arginine deprivation as a therapy to target arginine auxotrophic tumors.

Previous studies showed that arginine is converted by the cell to NO and polyamines that contribute to cell migration. However, the precise role of polyamines and NO are still poorly understood. Hence, further studies should be conducted to enhance our knowledge regarding the complex mechanisms that regulate NO's and polyamines' roles in tumor progression. Moreover, more studies should focus on the effect of arginine deprivation on other aspects including the function of peptidylarginine deiminases (PAD). Further studies should be done in order to investigate the relation between arginine deprived, PAD inhibition, and cell death. PAD isotypes are transcriptional co-regulators for various factors, including P53 and tumor growth gene erythropoietin (EPO). It is shown in many types of cancer cells that levels of PAD are elevated, and downregulating PAD hinders cancer cell's migration and proliferation capabilities [58, 59]. Thus, it would be interesting to study the effect of arginine depletion on PAD's activation in arginine auxotrophic cancer cells.

\begin{abstract}
Abbreviations
ADI: Arginine deaminase; ASL: Arginosuccinate lyase; ASS1: Arginosuccinate synthase-1; Co: Cobalt; CRC: Colorectal cancer; ECM: Extracellular matrix; EPO: Erythropoietin; FA: Focal adhesions; FAK: Focal adhesion kinases; GBM: Glioblastoma multiforme; HuArgl: Human L-arginase; MMP: Matrix metalloproteinase; NO: Nitric oxide; NOS: Nitric oxide synthase; OCT: Ornithine transcarbamylase; PAD: Peptidylarginine deiminase; PEG: Polyethylene glycol.
\end{abstract}

\section{Acknowledgements}

The work is supported by the Lebanese American University.

\section{Authors' contributions}

HAK, NEM and HM performed the literature review, wrote the review and helped with the revisions. MES and RAH wrote and edited the manuscript. All authors read and approved the final manuscript.

\section{Funding}

The work is supported by the Lebanese American University.

Availability of data and materials

Not applicable.

Ethics approval and consent to participate

Not applicable.

\section{Consent for publication}

Not applicable.

\section{Competing interests}

The authors declare the absence of any competing interests.

Received: 29 January 2020 Accepted: 23 April 2020

Published online: 06 May 2020

\section{References}

1. Al Hageh C, Al Assaad M, El Masri Z, Samaan N, El-Sibai M, Khalil C, Khnayzer RS. A long-lived cuprous bis-phenanthroline complex for the photodynamic therapy of cancer. Dalton Trans. 2018:47(14):4959-67.

2. Taitt HE. Global trends and prostate cancer: a review of incidence, detection, and mortality as influenced by race, ethnicity, and geographic location. Am J Men's Health. 2018;12(6):1807-23.

3. Abou-Antoun TJ, Hale JS, Lathia JD, Dombrowski SM. Brain cancer stem cells in adults and children: cell biology and therapeutic implications. Neurotherapeutics. 2017;14(2):372-84.

4. Saad A, Der-Nigoghossian CA, Njeim R, Sakr R, Salameh P, Massoud M. Prescription errors with chemotherapy: quality improvement through standardized order templates. Asian Pac J Cancer Prev. 2016;17(4):2329-36.

5. Abdallah MS, Kennedy CR, Stephan JS, Khalil PA, Mroueh M, Eid AA, Faour WH. Transforming growth factor- $\beta 1$ and phosphatases modulate COX-2 protein expression and TAU phosphorylation in cultured immortalized podocytes. Inflamm Res. 2018;67(2):191-201.

6. Abou-Antoun TJ, Nazarian J, Ghanem A, Vukmanovic S, Sandler AD. Molecular and functional analysis of anchorage independent, treatmentevasive neuroblastoma tumorspheres with enhanced malignant 
properties: a possible explanation for radio-therapy resistance. PLOS ONE. 2018;13(1):e0189711.

7. El-Amm J, Aragon-Ching JB. Targeting bone metastases in metastatic castration-resistant prostate cancer. Clin Med Insights Oncol. 2016. https ://doi.org/10.4137/CMO.Ss30751.

8. Hellerstedt BA, Pienta KJ. The current state of hormonal therapy for prostate cancer. CA Cancer J Clin. 2002;52(3):154-79.

9. Al Hassan M, Fakhoury I, El Masri Z, Ghazale N, Dennaoui R, El Atat O, Kanaan A, El-Sibai M. Metformin treatment inhibits motility and invasion of glioblastoma cancer cells. Anal Cell Pathol. 2018. https://doi. org/10.1155/2018/5917470.

10. Hanahan D, Weinberg RA. Hallmarks of cancer: the next generation. Cell. 2011;144(5):646-74.

11. Morris CR, Hamilton-Reeves J, Martindale RG, Sarav M, Ochoa Gautier JB. Acquired amino acid deficiencies: a focus on arginine and glutamine. Nutr Clin Pract. 2017;32:30S-47S

12. Fung MKL, Chan GC-F. Drug-induced amino acid deprivation as strategy for cancer therapy. J Hematol Oncol. 2017;10(1):144.

13. Fernandes H, Silva Teixeira C, Fernandes P, Ramos M, Cerqueira N. Amino acid deprivation using enzymes as a targeted therapy for cancer and viral infections. Expert Opin Ther Pat. 2017;27(3):283-97.

14. El-Sibai M, Pertz O, Pang H, Yip S-C, Lorenz M, Symons M, Condeelis JS, Hahn KM, Backer JM. RhoA/ROCK-mediated switching between Cdc42and Rac1-dependent protrusion in MTLn3 carcinoma cells. Exp Cell Res. 2008;314(7):1540-52.

15. Al-Dimassi S, Salloum G, Saykali B, Khoury O, Liu S, Leppla SH, Abi-Habib $\mathrm{R}$, El-Sibai M. Targeting the MAP kinase pathway in astrocytoma cells using a recombinant anthrax lethal toxin as a way to inhibit cell motility and invasion. Int J Oncol. 2016;48(5):1913-20.

16. Savaraj N, You M, Wu C, Wangpaichitr M, Kuo MT, Feun LG. Arginine deprivation, autophagy, apoptosis (AAA) for the treatment of melanoma. Curr Mol Med. 2010;10(4):405-12.

17. Nasreddine G, El-Sibai M, Abi-Habib RJ. Cytotoxicity of [HuArgl (co)PEG5000]-induced arginine deprivation to ovarian Cancer cells is autophagy dependent. Investig New Drugs. 2019;38:10-9.

18. Tanios R, Bekdash A, Kassab E, Stone E, Georgiou G, Frankel AE, Abi-Habib RJ. Human recombinant arginase I (Co)-PEG5000 [HuArgl (Co)-PEG5000]induced arginine depletion is selectively cytotoxic to human acute myeloid leukemia cells. Leuk Res. 2013;37(11):1565-71.

19. Glick D, Barth S, Macleod KF. Autophagy: cellular and molecular mechanisms. J Pathol. 2010;221(1):3-12.

20. Feun L, You M, Wu C, Kuo MT, Wangpaichitr M, Spector S, Savaraj N. Arginine deprivation as a targeted therapy for cancer. Curr Pharm Des. 2008;14(11):1049-57.

21. Shen L-J, Beloussow K, Shen W-C. Modulation of arginine metabolic pathways as the potential anti-tumor mechanism of recombinant arginine deiminase. Cancer Lett. 2006;231(1):30-5.

22. Feun LG, Kuo MT, Savaraj N. Arginine deprivation in cancer therapy. Curr Opin Clin Nutr Metab Care. 2015;18(1):78-82.

23. Lind DS. Arginine and cancer. J Nutr. 2004;134(10):2837S-41S.

24. Ensor CM, Holtsberg FW, Bomalaski JS, Clark MA. Pegylated arginine deiminase (ADI-SS PEG20, $000 \mathrm{mw}$ ) inhibits human melanomas and hepatocellular carcinomas in vitro and in vivo. Cancer Res. 2002;62(19):5443-50.

25. Qiu F, Chen Y-R, Liu X, Chu C-Y, Shen L-J, Xu J, Gaur S, Forman HJ, Zhang H, Zheng $\mathrm{S}$. Arginine starvation impairs mitochondrial respiratory function in ASS1-deficient breast cancer cells. Sci Signal. 2014;7(319):ra31.

26. Harris JM, Chess RB. Effect of pegylation on pharmaceuticals. Nat Rev Drug Discov. 2003;2(3):214.

27. Glazer ES, Stone EM, Zhu C, Massey KL, Hamir AN, Curley SA. Bioengineered human arginase I with enhanced activity and stability controls hepatocellular and pancreatic carcinoma xenografts. Transl Oncol. 2011;4(3):138.

28. Khalil N, Abi-Habib RJ. [HuArgl (co)-PEG5000]-induced arginine deprivation leads to autophagy dependent cell death in pancreatic cancer cells. Investig New Drugs. 2019. https://doi.org/10.1007/s10637-019-00883-4.

29. Al-Koussa H, Al-Haddad M, Abi-Habib R, El-Sibai M. Human recombinant arginase I [HuArgl (Co)-PEG5000]-Induced arginine depletion inhibits colorectal cancer cell migration and invasion. Int J Mol Sci. 2019;20(23):6018
30. Khoury O, Ghazale N, Stone E, El-Sibai M, Frankel AE, Abi-Habib RJ. Human recombinant arginase I (Co)-PEG5000 [HuArgl (Co)-PEG5000]-induced arginine depletion is selectively cytotoxic to human glioblastoma cells. J Neurooncol. 2015;122(1):75-85.

31. Mizushima N. Autophagy: process and function. Genes Dev. 2007;21(22):2861-73.

32. Shan Y-S, Hsu H-P, Lai M-D, Yen M-C, Chen W-C, Fang J-H, Weng T-Y, Chen Y-L. Argininosuccinate synthetase 1 suppression and arginine restriction inhibit cell migration in gastric cancer cell lines. Sci Rep. 2015;5:9783.

33. Ray RM, McCormack SA, Covington C, Viar MJ, Zheng Y, Johnson LR. The requirement for polyamines for intestinal epithelial cell migration is mediated through Rac1. J Biol Chem. 2003;278(15):13039-46.

34. Spitler R, Schwappacher R, Wu T, Kong X, Yokomori K, Pilz RB, Boss GR, Berns MW. Nitrosyl-cobinamide (NO-Cbi), a new nitric oxide donor, improves wound healing through cGMP/cGMP-dependent protein kinase. Cell Signal. 2013;25(12):2374-82.

35. Zhan R, He W, Wang F, Yao Z, Tan J, Xu R, Zhou J, Wang Y, Li H, Wu J. Nitric oxide promotes epidermal stem cell migration via cGMP-Rho GTPase signalling. Sci Rep. 2016;6:30687.

36. Rhoads J, Chen W, Gookin J, Wu G, Fu Q, Blikslager A, Rippe R, Argenzio R, Cance W, Weaver E. Arginine stimulates intestinal cell migration through a focal adhesion kinase dependent mechanism. Gut. 2004;53(4):514-22.

37. Noiri E, Peresleni T, Srivastava N, Weber P, Bahou WF, Peunova N, Goligorsky MS. Nitric oxide is necessary for a switch from stationary to locomoting phenotype in epithelial cells. Am J Physiol Cell Physiol. 1996;270(3):C794-802.

38. Case LB, Waterman CM. Integration of actin dynamics and cell adhesion by a three-dimensional, mechanosensitive molecular clutch. Nat Cell Biol. 2015;17(8):955.

39. Sanders MA, Basson MD. Collagen IV-dependent ERK activation in human Caco-2 intestinal epithelial cells requires focal adhesion kinase. J Biol Chem. 2000;275(48):38040-7.

40. Vandenberg CA. Integrins step up the pace of cell migration through polyamines and potassium channels. Proc Natl Acad Sci. 2008:105(20):7109-10.

41. Assémat E, Bazellières E, Pallesi-Pocachard E, Le Bivic A, Massey-Harroche D. Polarity complex proteins. Biochim Biophys Acta Biomembr. 2008:1778(3):614-30

42. Riveline D, Thiagarajan R, Lehn J-M, Carlier M-F. Synthetic polyamines: new compounds specific to actin dynamics for mammalian cell and fission yeast. BioArchitecture. 2014;4(4-5):144-8.

43. Johnson DA, Fields C, Fallon A, Fitzgerald ME, Viar MJ, Johnson LR. Polyamine-dependent migration of retinal pigment epithelial cells. Invest Ophthalmol Vis Sci. 2002;43(4):1228-33.

44. Kucharzewska P, Welch JE, Svensson KJ, Belting M. Ornithine decarboxylase and extracellular polyamines regulate microvascular sprouting and actin cytoskeleton dynamics in endothelial cells. Exp Cell Res. 2010;316(16):2683-91.

45. You J, Chen W, Chen J, Zheng Q, Dong J, Zhu Y. The oncogenic role of ARG1 in progression and metastasis of hepatocellular carcinoma. BioMed Res Int. 2018. https://doi.org/10.1155/2018/2109865.

46. Kessenbrock K, Plaks V, Werb Z. Matrix metalloproteinases: regulators of the tumor microenvironment. Cell. 2010;141(1):52-67.

47. Stamenkovic I. Matrix metalloproteinases in tumor invasion and metastasis. In: Seminars in cancer biology: 2000. Elsevier; 2000: 415-433.

48. Shay G, Lynch CC, Fingleton B. Moving targets: emerging roles for MMPs in cancer progression and metastasis. Matrix Biol. 2015;44:200-6.

49. Merlot S, Meili R, Pagliarini DJ, Maehama T, Dixon JE, Firtel RA. A PTENrelated 5-phosphatidylinositol phosphatase localized in the Golgi. J Biol Chem. 2003:278(41):39866-73.

50. Song MS, Salmena L, Pandolfi PP. The functions and regulation of the PTEN tumour suppressor. Nat Rev Mol Cell Biol. 2012;13(5):283.

51. Aspenström P. The intrinsic gdp/gtp exchange activities of $\mathrm{Cdc} 42$ and rac1 are critical determinants for their specific effects on mobilization of the actin filament system. Cells. 2019;8(7):759.

52. DePasquale JA, Izzard CS. Evidence for an actin-containing cytoplasmic precursor of the focal contact and the timing of incorporation of vinculin at the focal contact. J Cell Biol. 1987:105(6):2803-9.

53. Fostok SF, El-Sibai M, El-Sabban M, Talhouk RS. Gap junctions and Wnt signaling in the mammary gland: a cross-talk? J Mammary Gland Biol Neoplasia. 2019;24(1):17-38. 
54. Guo F, Debidda M, Yang L, Williams DA, Zheng Y. Genetic deletion of Rac1 GTPase reveals its critical role in actin stress fiber formation and focal adhesion complex assembly. J Biol Chem. 2006;281 (27):18652-9.

55. Sedgwick A, D'Souza-Schorey C. Wnt signaling in cell motility and invasion: drawing parallels between development and cancer. Cancers. 2016;8(9):80.

56. Zhou J, Dehne N, Brüne B. Nitric oxide causes macrophage migration via the HIF-1-stimulated small GTPases Cdc42 and Rac1. Free Radic Biol Med. 2009;47(6):741-9.

57. Fujita M, Imadome K, Endo S, Shoji Y, Yamada S, Imai T. Nitric oxide increases the invasion of pancreatic cancer cells via activation of the PI3K-AKT and RhoA pathways after carbon ion irradiation. FEBS Lett. 2014;588(17):3240-50
58. Horibata S, Rogers KE, Sadegh D, Anguish LJ, McElwee JL, Shah P, Thompson PR, Coonrod SA. Role of peptidylarginine deiminase 2 (PAD2) in mammary carcinoma cell migration. BMC Cancer. 2017;17(1):378.

59. Lange S, Gallagher M, Kholia S, Kosgodage U, Hristova M, Hardy J, Inal J. Peptidylarginine deiminases - roles in cancer and neurodegeneration and possible avenues for therapeutic intervention via modulation of exosome and microvesicle (EMV) release? Int J Mol Sci. 2017;18(6):1196.

\section{Publisher's Note}

Springer Nature remains neutral with regard to jurisdictional claims in published maps and institutional affiliations.
Ready to submit your research? Choose BMC and benefit from:

- fast, convenient online submission

- thorough peer review by experienced researchers in your field

- rapid publication on acceptance

- support for research data, including large and complex data types

- gold Open Access which fosters wider collaboration and increased citations

- maximum visibility for your research: over $100 \mathrm{M}$ website views per year

At BMC, research is always in progress.

Learn more biomedcentral.com/submissions 